\title{
Analyzing resilience of urban networks: a preliminary step towards more flood resilient cities
}

\author{
S. Lhomme ${ }^{1,2}$, D. Serre ${ }^{1}$, Y. Diab ${ }^{1,3}$, and R. Laganier ${ }^{2}$ \\ ${ }^{1}$ Université Paris EST (EIVP), Paris, France \\ ${ }^{2}$ Université Paris Diderot (PRODIG), Paris, France \\ ${ }^{3}$ Université Paris EST (LEESU), Paris, France
}

Correspondence to: S. Lhomme (serge.lhomme@eivp-paris.fr)

Received: 5 March 2012 - Published in Nat. Hazards Earth Syst. Sci. Discuss.: -

Revised: 5 October 2012 - Accepted: 23 November 2012 - Published: 6 February 2013

\begin{abstract}
In Europe, river floods have been increasing in frequency and severity. These circumstances require the management of flood risk by integrating new concepts like urban resilience. Nevertheless, urban resilience seems to have no accurate meanings. That is why researchers are primarily concerned with defining resilience. Nevertheless, focus on research object seems to be more important than focus on conceptual debate (Resilience of what? Rather than what is resilience?). Thus the methodology designed here is focused on urban considerations. In fact, a system approach emphasizes technical networks' importance concerning urban resilience. Principles and assumptions applied in this research finally lead to the analysis of how urban networks are able to face natural hazards. In this context, a Web-GIS has been developed for analyzing resistance capacity, absorption capacity and recovery capacity of different technical networks. A first application has been carried out on a French agglomeration in order to analyze road network absorption capacity. This application is very specific but, thanks to this example, it is already possible to highlight the methodology's usefulness.
\end{abstract}

\section{Introduction}

Floods still cause a lot of damage and many casualties, although people have tried to reduce flood impacts for many centuries (De Bruijn, 2005). Moreover, climate change is expected to exacerbate the frequency and intensity of hydro meteorological disaster. Despite efforts made to maintain the flood defense assets, we often observe levee failures, ulti- mately leading to increased flood risk in protected areas. Furthermore, flood forecasting models, although benefiting continuous improvements, remain partly inaccurate due to uncertainties arising all along data calculation processes.

At the same time, the year 2007 marks a turning point in history: half of the world population now lives in cities (Zevenbergen et al., 2010). This growing rate is equivalent to the creation of a new city of one million inhabitants every week, and this during the next four decades (Flood resilience Group). Thus, quick urban development coupled with technical failures and climate change have increased flood risk and corresponding challenges to urban flood risk management (Ashley et al., 2007). These circumstances require the management of flood risk by integrating new concepts like urban resilience.

Resilience is "fashionable", particularly with scientists, administrators and international authorities in charge of preventing disasters. Some researchers consider resilience a "buzzword" and see its consecration with September 11 and Katrina (Comfort at al., 2010). Other researchers rather emphasize its link with papers and concerns on climate change (Klein et al., 2003). In any case, the omnipresence of resilience makes one wonder about its pertinence. In fact, the abundant use of the concept, especially in the Social Sciences, does not always come with a solid theoretical base. The word then becomes an umbrella term used with a variety of meanings, just like other fashionable concepts (sustainability, governance...) that are often used in relation to it (Gallopin, 2006). In this context, it is rather difficult to get a common definition and to design methodology in order to implement this concept in an operational way. That is 
why the main objective of this research is to design methodology and tools for analyzing urban resilience. This paper introduces a new methodology for analyzing urban resilience and explains why this methodology is focused on technical networks' resilience analysis.

First a definition of urban resilience will be introduced in order to later focus on the research object (the city) and move forward toward conceptual debate. Then, starting from a systematic approach of the city, a methodology is proposed for studying urban resilience. Then, thanks to the development of a Web-GIS tool, the methodology can be implemented. To conclude, application on a French agglomeration will be presented. This application is focused on the absorption capacity analysis of the road network, which is based on new redundancy indicators. Thus, this application highlights a very specific development required to implement the methodology.

\section{Resilience: a theoretical overview}

Derived from ecology, the concept of resilience is chiefly defined as "the measure of the persistence of systems and of their ability to absorb change and disturbance and still maintain the same relationships between populations or state variables" (Holling, 1973). The concept of resilience has a rich history (Folke, 2006), sometimes with a considerable stretch from its original meaning (Gallopin, 2006). Thus, it is possible to identify a sequence of resilience concepts in ecology, from narrow to broad: engineering resilience, ecosystem resilience, social-ecological resilience (Folke, 2006). Indeed, the most important development over the past thirty years is the increasing recognition across the disciplines that human and ecological systems are interlinked and that their resilience relates to the functioning and interaction of the systems rather than to the stability of their components or the ability to maintain or return to some equilibrium state (Klein et al., 2003). Henceforth, the concept is used by various scientific disciplines and there is a tension between the original descriptive concept of resilience first defined in ecological science and a more recent, vague, and malleable notion of resilience used as an approach or boundary object by different scientific disciplines (Brand and Jax, 2007).

The polysemy of the resilience concept is not a problem in itself; it is even productive in terms of heuristic and methodological issues (Folke, 2006). The difficulties arise when the polysemy seems to legitimize a semantic blur that creates theoretical and operational dead ends. In view of occasional contrary injunctions, the concept is "inoperative" and reduced to some sort of unattainable discursive utopia, to the point where some researchers have considered the concept too vague to be used in order to prevent disaster (Manyena, 2006).

The first issue comes from formalization in order to make the concept operational. The consecration of resilience could be interpreted as an answer to operational dead ends. Certainly, the pertinence of a theoretical concept lies essentially
Table 1. Terms used in the definitions of resilience in relation to natural hazards, according to the definitions selected in Mayunga (2007).

\begin{tabular}{lclc}
\hline Terms & Occurrences & Terms & Occurrences \\
\hline Adapt & 2 & Cope with & 4 \\
Absorb & 1 & Recover & 8 \\
Withstand & 3 & Maintain & 1 \\
Return & 1 & Bounce back & 1 \\
\hline
\end{tabular}

in its heuristic potential or its hermeneutic power and not in its purely practical efficiency. Nevertheless, resilience was immediately seen as an opportunity to enrich or even renew the management systems such as the policies contributing to reduce hazards and disasters. It must be emphasized that hazard research can hardly be independent from this passage from theory to practice.

These formalizing difficulties have an immediate consequence: in practice, many interpretations are incompatible. For example, when the very poor are the first to come back to the disaster areas after an impact, some see a proof of their resilience, others of their vulnerability, others still of the metropolitan system's inertia or of the captivity of those populations (even if those categories do not necessarily correspond to reality; Reghezza et al., 2012). Moreover, in the literature, it becomes evident that, to be resilient, a system must, at the same time, be redundant, diversified and efficient; autonomous and collaborative; i.e., stiff, flexible and adaptable; capable of learning from the past and of facing future uncertainties. To some extent these characteristics are contradictory. Thus concerning the different linkage between resilience, vulnerability and adaptive capacity concept, a didactic review has been already done (Cutter et al., 2008).

Nevertheless, beyond this polysemy, there are many common definitions. For instance, some articles outline numerous resilience definitions (Mayunga, 2007) and it appears that there are many redundancies (Table 1). So, thanks to the study of many definitions in different disciplines, we have defined urban resilience, in our context of research, as "the ability of a city to absorb disturbance and recover its functions after a disturbance" (Lhomme et al., 2011). In other words, urban resilience can be defined as the ability of a city to operate in a degraded mode (absorption capacity) and to recover its functions, despite the fact that some urban components are disrupted (recovery capacity; Lhomme et al., 2011).

So, defining urban resilience is not necessarily the main issue. In fact, operational research needs to go beyond semantic debate. If a concept offers a specific lens for analyzing an object, this lens can change over time and disciplines. In this context, there is an imperious need to develop a methodology that focuses on the research object rather than on the concept itself. Thus, the main question is: resilience of what (Carpenter et al., 2001) rather than what is resilience? 


\section{Methodology and tool for assessing urban resilience based on system approach of the city}

To go beyond the definition debate concerning resilience, a focus on the research object is needed.

Yet, if the concept of a city seems perfectly clear to everyone, defining this concept is complex. For instance, the definition of a city has been approached in a number of distinct ways. Among the more important viewpoints that have been adopted are the economic, the sociological, the cultural and the historical. There is no one standard definition of a city: the term may be used for a town possessing city status; for an urban locality exceeding an arbitrary population size; or for a town dominating other towns with particular regional economic or administrative significance. System approach tends to overcome these segmentations and level of complexity. Indeed, a system approach proposes a common language for different disciplines and can be considered a good way to study complex system (Batty, 2009).

\subsection{Urban networks: a major issue for flood resilient cities}

Urban resilience is often defined as "the capacity of a city to face devastating event reducing damage at minimum" (Campanella, 2006). This definition emphasizes the operational aspect of resilience that would tend to reduce the damage caused by a disturbance; but in this context resilience doesn't really appear as a new concept, because city managers have tended to reduce damages for several decades. Moreover, this definition of resilience cannot be linked directly with other disciplines which use a resilience concept.

Concerning flood hazards, resilience concepts are comprised of individual preventive and emergency measures at building scale and a land use policy to adapt building activities to floods (Pasche and Geisler, 2005). That is why, for some researchers, flood preparedness is mainly a matter of flood-resilient building and hazard awareness. So, in the current discussion on flood resilient cities, a strong emphasis is placed on improving the flood performance of buildings. Nevertheless, a resilience concept was also applied to flood risk management by adopting a systems approach (De Bruijn, 2005). In this context, the city has to be considered as an entity composed by different elements and not merely as a set of concrete buildings. Henceforth, it is acknowledged that it is an interesting and useful exercise to think of a city as a system (Zevenbergen et al., 2010).

A system model has been designed for studying cities and for modeling their functions. In this model, the city is composed of different elements such as population, companies, public infrastructures, housing and networks (Lhomme et al., 2010). These components are supported by the environment and they are organized by governance. Moreover, urban systems are subjected to influences from the external world (systems environment), for example, eco- nomic shocks, technological advances, and political changes. System relations with its environment are characterized by exchanges with other cities (raw materials, manufactured goods...) and of course the waste produced by activities and population (Lhomme et al., 2010).

In this system, the power and influence of a city are based on its ability to provide a safe environment for its citizens and an efficient support for its activities. Urbanity is then linked with resources accumulation enabled by economic activities that depend on powerful networks (Blancher, 1998). Moreover, networks play an important part in crises and not always for positive aspects. Recent experience feedbacks have highlighted the negative role of technical networks during a crisis. The first manifestation is the extension of networks that propagate the failure. For instance, if an urban heating network encounters a disruption, the whole district would be deprived of heating, whereas if each building has its own heating device, an impact would be restricted to the building. So, evaluating network infrastructures for potential vulnerabilities is an important component of strategic planning, particularly in the context of managing and mitigating service disruptions (Matisziw et al., 2008). For instance, the reliability and rapid restoration of the electric grid in particular is necessary to support the needs of the population within the disaster area effectively (Winkler et al., 2010).

Concerning flood hazards, experiences coming from Great Britain give good examples of technical networks vulnerability to flooding. The severe flooding in June and July 2007 left many homes and businesses without power and water for days. Gloucestershire was particularly badly hit, with half a million people threatened by power cuts and water shortages as Walham sub-station and Mythe water treatment works flooded. At Walham sub-station, after almost $10 \mathrm{~h}$ the site was secured and the fire and rescue services began pumping water out of the critical area. The work was completed just in time, narrowly averting a major shutdown of the site, which could have left half a million homes without power. Castle Mead sub-station was less fortunate and power to 42000 homes was cut whilst temporary defenses were put in place (EA-UK, 2007).

The experiences at Walham, Castle Mead and Mythe have highlighted the very real need to protect technical networks from the impact of flooding. Whilst Gloucestershire was particularly badly affected, many other parts of the country also suffered major disruption. In Yorkshire alone, 136 sewage treatment works, serving two million people, were flooded during June. Mythe water treatment works was also severely affected. The site supplies water to around 350000 people in Tewksbury, Cheltenham and Gloucester. Up to half a meter of flood water covered the site, flooding buildings, offices and equipment, and preventing staff from safely returning for three days (EA-UK, 2007).

A new paradigm in urban risk management needs new methods to shift from conceptual analysis toward operational tools. Because societal functions are highly dependent on 
networked systems and at the same time the operability of these systems can be vulnerable to disasters, there is a need to understand how networked systems are resilient. When improving urban resilience, improving the networks' resilience seems to be a necessary (but not sufficient) condition. Indeed, networks are at the same time vectors of development and vectors of failure propagation. If a city is to face risks, it must have resilient networks to ensure its basic functioning and to foster a quick recovery.

The methodology designed here for analyzing urban resilience suggests focusing on a technical network resilience analysis. Thus, thanks to this focus on urban technical networks, it is possible to identify the most critical locations and then to prioritize actions to protect these locations, in particular if these locations include many critical infrastructures.

\subsection{A framework for assessing the resilience level of the urban networks}

Using the resilience definition, three capacities need to be analyzed for studying resilience: absorption capacity, recovery capacity and resistance capacity. Absorption capacity is the ability of a network to redistribute flows toward undamaged parts of the network when this network is partly damaged. In other words, a resilient network should be redundant (Ouyang et al., 2012). Furthermore, this network should not be completely damaged (and consequently out of service) despite a good redundancy. So, a resilient network should also be resistant. Recovery capacity of a technical network corresponds to its ability to restore damaged components. This capacity may correspond to the time required for restoration of damaged components. Recovery capacity is directly related to network damages because if the network is highly damaged, it will be difficult to quickly restore all the damaged components. In fact, absorption capacity and recovery capacity can be considered as dependant of resistance capacity. That is why resistance capacity has been introduced as the third capacity requirement for network resilience (Fig. 1), in addition to absorption and recovery capacities that are directly involved in resilience definition.

For each capacity, some methodological choices have been undertaken. Thus, absorption capacity analysis is focused on networks' redundancy assessment. Resistance capacity analyzes dysfunctions induced by damaged components and takes into account interdependencies between networks (Lhomme et al., 2011). Recovery capacity analysis considers accessibility between restoration center and damaged components.

This framework is quite similar to existing approaches' focus on infrastructure resilience analysis (Bruneau et al., 2003; Ouyang et al., 2012). Yet, beyond similarities, these approaches are quite different in terms of infrastructures studied (Bruneau et al., 2003) or in terms of methods used for implementing these approaches (Ouyang et al., 2012).

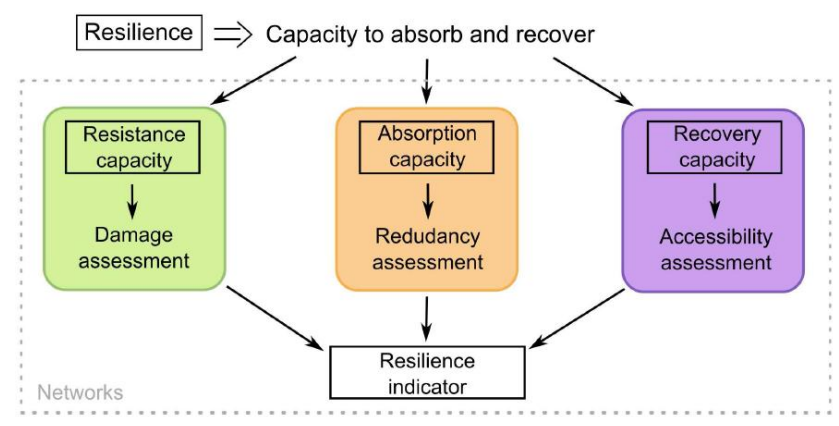

Fig. 1. Strategy for assessing networks resiliency.

\subsection{A web GIS for implementing the overall methodology}

A Geographic Information System (GIS) is required to implement the methodology presented above. A GIS is a mapping software that provides spatial information by linking locations with information about that location. It provides the functions and tools needed to efficiently capture, store, manipulate, analyze, and display the information about places and things. First, this research focuses on urban technical networks. Technical networks (i.e., transportation networks, the Internet) connect points in geographic space. Thus, the nodes and the edges (lines) of these networks are real physical constructs occupying particular positions in space. So, researchers find that there are strong signatures in these networks of topography and use patterns, giving the networks shapes that are quite distinct from one another and from nongeographic networks (Gastner and Newman, 2006).

Secondly, it is well known that GIS can be used to analyze the spatial component of risk and it is clear that risk assessments have an important spatial component. For instance, to better respond to post-disaster activities, geographic information system (GIS) technology provides a logical tool for integrating the necessary information and contributing to preparedness, rescue, relief, recovery and reconstruction effort (Gunes and Kovel, 2000; Lembo et al., 2008). That is why a GIS has been designed in order to analyze the resilience of urban technical networks and to finally implement the overall methodology.

This GIS is a Web-GIS because it is interesting to design a portable solution independent of proprietary software. Architecture of this Web-GIS is based on four main components: a database storing the data required for calculations (like the network, and major issues) and the results (Fig. 2); a web server to deliver web content; a map server for mapping application; and a user interface displaying results. Interface is composed by 5 different modules with respect to the methodology and the strategy for assessing networks resiliency (Fig. 3). Thus, the interface menu proposes a fourstep analysis: first the absorption capacity analysis; second the resistance capacity analysis; third the recovery capacity 


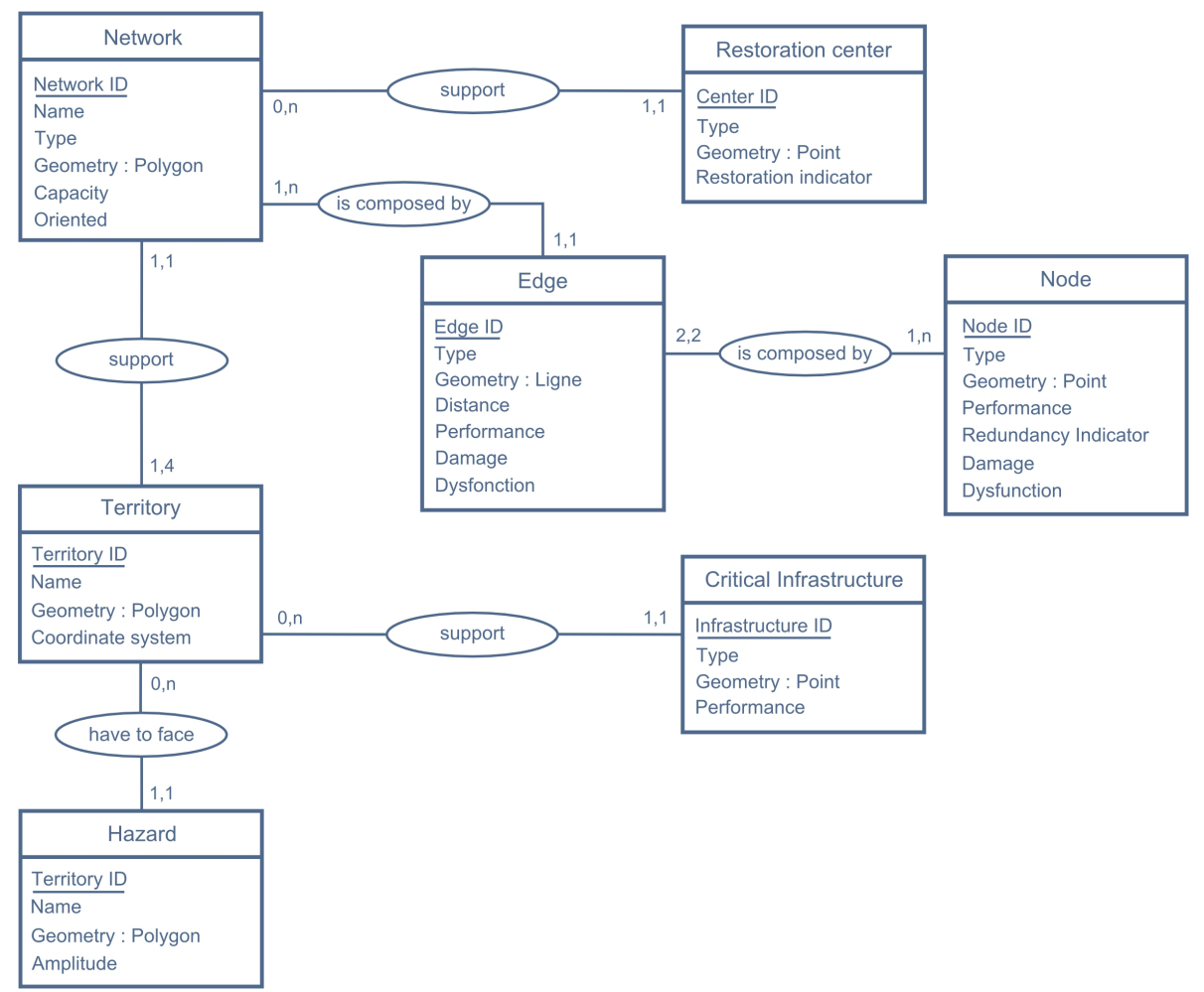

Fig. 2. Entity-relationship model for the Web-GIS database.

analysis; and to conclude a synthesis of the different results with the introduction of critical infrastructures location analysis.

\section{Application: Orleans road network absorption capacity}

Data on technical networks are difficult to obtain, especially at the city level. In the city of Orléans, networks are managed by several private institutions, which are reluctant to provide data for both security (terrorism, sabotage) and competitive reasons. That is why the city of Orléans is involved with the local state authority for the crisis management of networks infrastructures.

However, road network data can be easily obtained. Moreover, absorption capacity can be studied using few data, because this capacity can be considered as a network structural property, which is not focused on flow dynamics and specific scenarios (for instance floods hazards) but on network topology (Gleyze, 2005). In this context, the first step of our methodology is generally to study the absorption capacity of road networks.

\subsection{Structural analysis of technical networks}

Technical networks - such as power grid networks, internet and pipelines - are more and more important in modern so- ciety. These networked infrastructures are considered as a branch of the complex networks which also include biological and social networks. Related research originating from the complex networks have attracted increasing attention in recent decades (Zhang et al., 2012). In particular, there has been considerable interest within the physics community in the analysis of this complex networks (Zhang et al., 2012). Thus, extensive research into the properties and behaviors of complex systems has uncovered surprising commonalities among the topologies of different systems. This exploration has also underscored the need to move beyond reductionist approaches, trying, instead, to understand the behavior of a system as a whole. Attempts to explain similarities have led to the ongoing development and refinement of network models and graph-theoretical analysis techniques with which to characterize and understand complexity (for instance, scale free and small world properties).

Although these studies are generally theoretical, they have been conducted with the hope of finding properties and behaviors that transcend abstraction (Albert et al., 2004). That is why there is a specific interest in network infrastructures which are not abstract constructions. These infrastructures offer concrete applications for this structural (topological) analysis. For instance, physicists have recently made substantial progress in the understanding of electrical power-grids (Albert et al., 2004; Kinney et al., 2005; Sole et al., 2008). Thus, the relationship between structure 


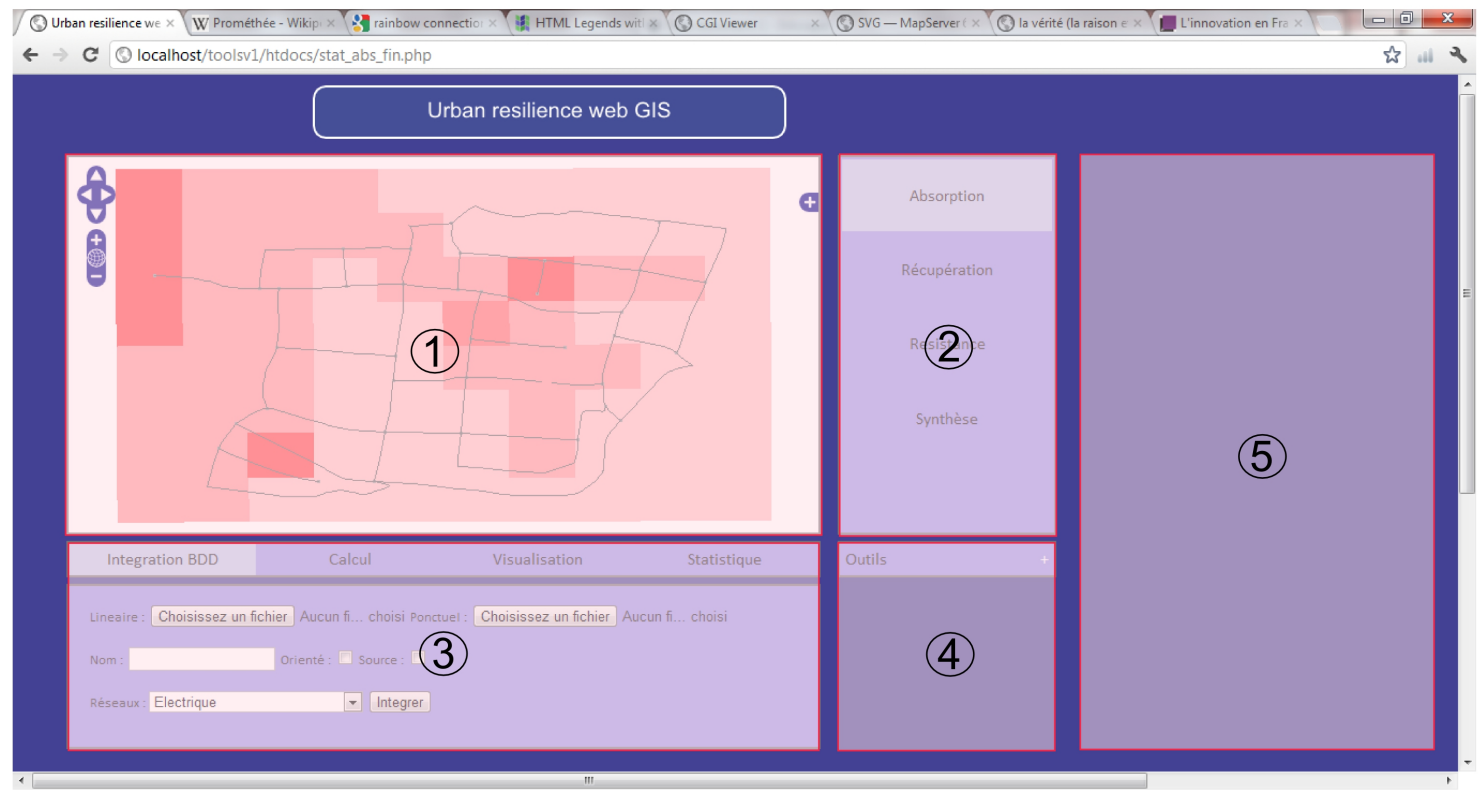

Fig. 3. Web-GIS user interface: The map (1); The menu (2); Options of each menu (3); Different tools (4); Information about map objects (5).

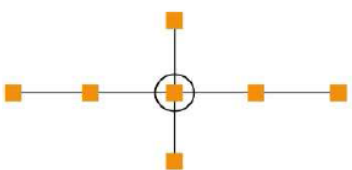

Redundancy ratio $<0,10$

Indicator $1=1$

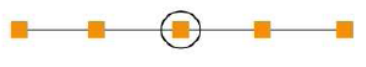

Redundancy ratio $=0,125$

Indicator $1=1$

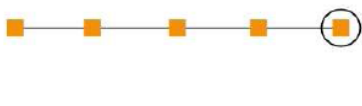

Redundancy ratio $>0,20$

Indicator $1=1$

Fig. 4. Correction of some abnormalities.

and performance in networks has implications for managing and mitigating risks related to network attacks or failures (Garber, 2000), whereas other researchers used a topological model of cascading failure and argue that attacks on nodes (buses) transporting smaller amounts of power can result in disproportionately large failures (Wang and Rong, 2009).

This focus on topology (structural analysis) is relatively new. While they do provide insight into network structure, these studies neglect the equations that govern flows (Hines and Cotilla Sanchez, 2010). In fact, dimensioning methods, based on flow modeling, are used by engineers and technicians to decide which solution is best for the construction of a network. They consider the environment (i.e., temperatures, soil nature, soil use), the population supplied by the service (i.e., number, type, habits), the techniques and the costs associated. The analysis of all those data is supposed to lead to the best solution. The methods used by engineers and technicians to determine the characteristics of the network take into account the needs (assessed with the social context), the environment (including the risks), the different techniques available, and the costs. Traditionally, the princi- ple in technical networks hazard assessment is a comparison between the flow during normal working conditions and under disruption. This traditional approach based on flow can be considered as functional analysis, whereas relatively new approach based on topology can be considered as structural analysis (Gleyze, 2005).

\subsection{New redundancy indicators for assessing networks absorption capacity}

Concepts coming from graph theory are fundamental to assess observable differences in network topology and flow types. A graph is a very simple structure consisting of a set of vertices and a family of lines, called edges (undirected) or arcs (directed), each of them linking some pair of vertices.

A network is notably characterized by a specific capacity to absorb different type of disturbance. Most of the frequent disruptions are always locally absorbed by the networks and the end users remain unaware of their occurrence (DueñasOsorio, 2005). This fact results from the ability of the networks to redistribute the flow at the location of the disruption. This is a typical resilience capacity that allows networks to 
operate in a degraded mode. Thus, network geometric properties limit adaptive capacity of this network. Indeed, network configuration (structural property) determines the number of alternative paths to the disruptions of one or several components. This network property can be considered as the redundancy of the networks. In fact, redundancy is a common property for characterizing resilient networks (Serulle, 2010).

So, the objective here is to investigate network representations of the technical networks from a topological (structural) perspective in order to study redundancy of these networks and consequently to discriminate nodes (or edges) in terms of redundancy.

Some indicators already exist to discriminate nodes (or edges) in terms of redundancy. For instance, the clustering coefficient, also known as transitivity, is a typical property of acquaintance networks, where two individuals with a common friend are likely to know each other (Wasserman and Faust, 1994). The clustering coefficient is a measure of the degree to which nodes in a graph tend to cluster together and characterize the cohesiveness of the neighborhood of a node. Thus, this indicator is close to the redundancy characterization. Such a quantity is not suited to characterize the local properties of a planar graph, since by a simple counting of the number of triangles present in the graph, it is not possible to discriminate different technical network topologies. For instance, there are cases as diverse as trees, square-meshes and honey-comb meshes, all having the same clustering coefficient equal to zero. Researchers have proposed a more general measure of the structure of cycles (not restricted to cycles of length 3) in planar graphs, the so-called meshedness coefficient (Buhl et al., 2006). Nevertheless, this last indicator is a global indicator and it can't discriminate nodes (or edges) in terms of redundancy.

The redundancy ratio, defined in (Dueñas-Osorio, 2005), assesses the redundancy of a network. In this research, redundancy is characterized by the number of "independent" relationships $(I(v, j))$ to go from one point $(v)$ to the neighbors of the neighbors of this point $\left(\Gamma^{2}(v)\right)$. So, it is proposed to count all the independent paths linking one point and the set of neighbors of its neighbors and then to divide this proportion by the number of links that could possibly exist between them. This is a good global indicator to characterize redundancy of a network, but it presents some abnormalities at a local scale due again to planar configuration of technical networks (Fig. 4). That is why this indicator is not useful at the local scale. In fact, to correct these abnormalities, it is possible to average the proportion of independent paths linking one point and the set of neighbors of its neighbors $\left(V\left[\Gamma^{2}(v)\right]\right.$ is the number of neighbors of neighbors). This average indicator is the first indicator used to analyze absorption capacity (Indicator $1(v)$ ); Eq. (1).

Nevertheless, this indicator is not sufficient to characterize technical network redundancy. Indeed each point is considered as an origin or a destination point, but in many cases these points are used as "connection points". So, technical network redundancy is highly concerned by transitivity issues. Thus, redundancy corresponds to a second indicator, corresponding to the number of independent paths between the neighbors of the neighbors, to a point when this point is disturbed (Indicator $2(v)$ ); Eq. (2). Each indicator considers the quality of alternatives (a comparison with the best path, for instance with the shortest path $\operatorname{Min}(\sigma(I(v, j)))$. Moreover, this indicator can be based on other criteria than distance: i.e., capacity for water network, or impedance for electricity network. It is also possible to adapt these indicators to work at another scale $\left(V\left[\Gamma^{3}(v)\right] ; V\left[\Gamma^{4}(v)\right] ; \ldots ; \mathrm{V}\left[\Gamma^{n}(v)\right]\right)$;

Indicator $1=\frac{1}{V\left[\Gamma^{2}(v)\right]} \sum_{j \in \Gamma^{2} ; j \neq v} \frac{\sigma(I(v, j))}{\operatorname{Min}(\sigma(I(v, j)))}$

Indicator $2=\frac{1}{\left(V\left[\Gamma^{2}(v)\right]\right)\left(V\left[\Gamma^{2}(v)\right]-1\right)} \sum_{i, j \in \Gamma^{2}(v) ; i, j \neq v} \frac{\sigma(I(i, j))}{\operatorname{Min}(\sigma(I(i, j)))}$

\subsection{Redundancy of Orleans road network}

Orléans is a city in north-central France, about $130 \mathrm{~km}$ southwest of Paris. It is the capital of the Loiret department and of the Centre region. Orléans is located on the Loire River. The Loire River crosses the agglomeration from east to west. In Orléans, the Loire is separated by a submerged dike into the "Grande Loire" to the north, no longer navigable, and the "Petite Loire" to the south. This dike is just one part of a vast system of construction that previously allowed the Loire to remain navigable. 14 municipalities (over 22 from Orléans' administrative district) are concerned by the Loire River floods, corresponding to about 19000 households which could experience water levels higher than $1.50 \mathrm{~m}$. The city of Orléans was completely flooded three times in the 19th century. More recently, in 2003, the Loire upstream Orleans partly overflowed some urban and countryside areas.

Today, Orleans is committed to reducing its vulnerability by taking new adaptive approaches to sustainable flood risk management and flood risk management planning. During recent years, the city of Orleans has been working on flood issues through information campaigns, spreading knowledge about floods in the communities and raising awareness. It is also putting in place rescue and recovery plans for the population and public services. The aim is to minimize damages and enable the city to recover as quickly as possible after flood events. In fact, Agglomeration of Orleans is one of the most advanced territories in France in terms of vulnerability concerns. Flood managers understood very early that, in a context of a diked system, trying to tackle the question of residual risk (e.g. flood defense failure) is essential to produce resilient cities. So, they have been interested in an application of the methodology on their territory.

First, this application will focus on two cities close to the City of Orléans to demonstrate usefulness of the two redundancy indicators designed. These indicators have been calculated and classifications in four different classes have been 


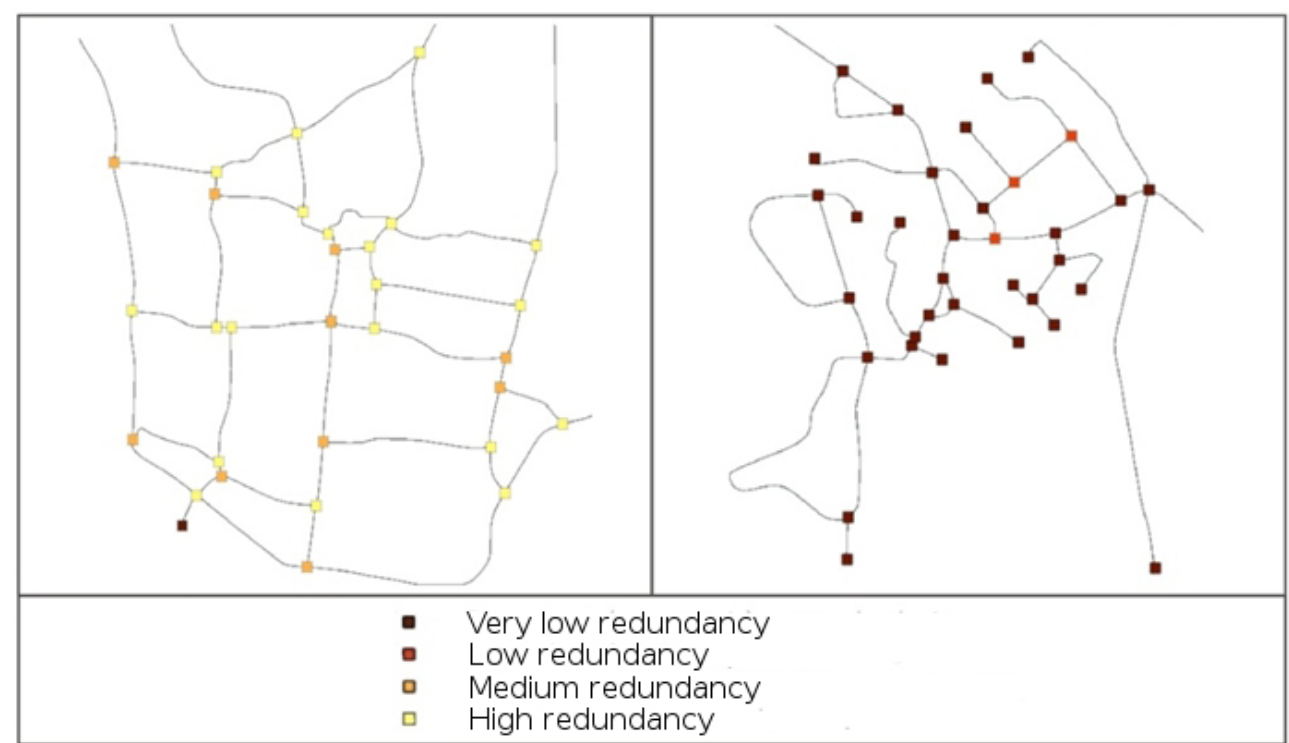

Fig. 5. Orleans road networks redundancy; the city of Bou (left) and the city of Chanteau (right).

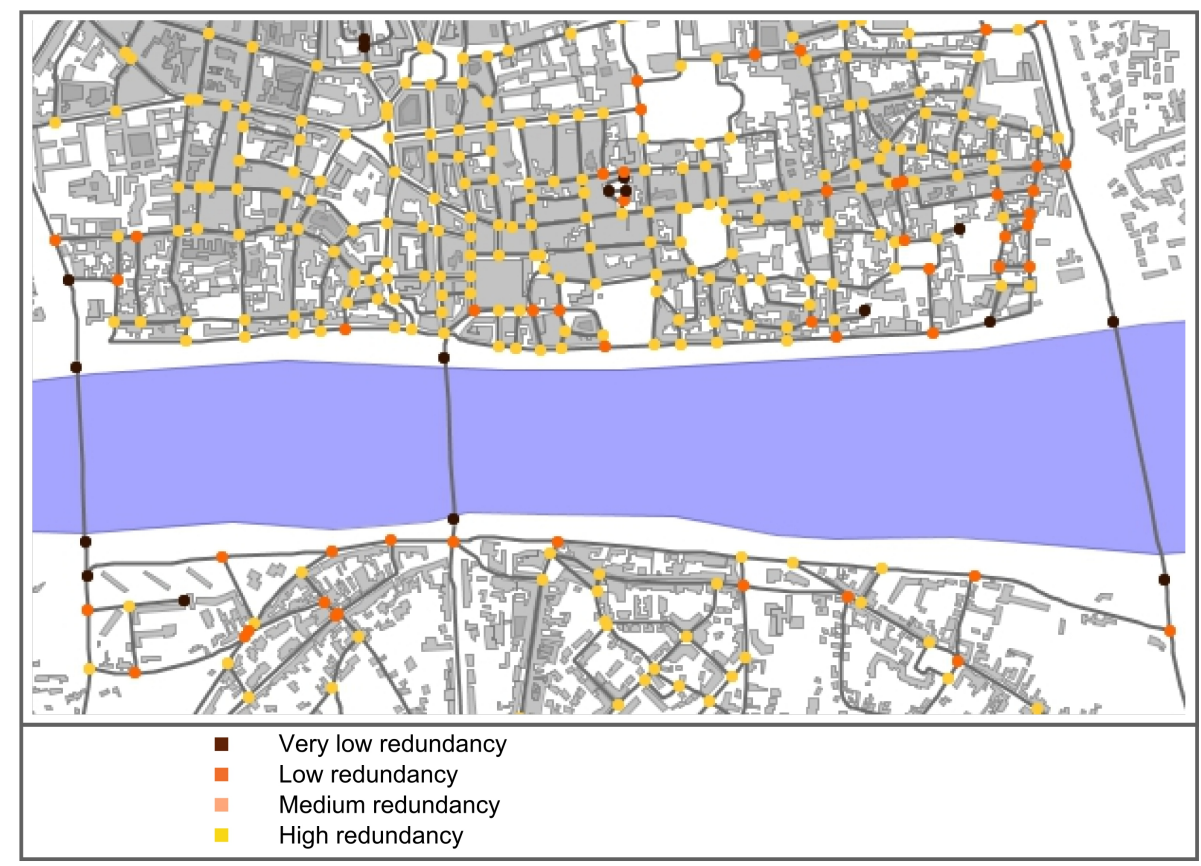

Fig. 6. Orleans road networks redundancy analysis shows the weak redundancy of this network close to bridges.

carried out for each indicator. Thus two different maps have been obtained for each city. Then, the results have been aggregated to obtain a single map for each city. For this, for each node (corresponding to road intersections), the less redundant classification is chosen to characterize redundancy. Thus, the two maps below show the differences of redundancy between the two cities in a very simple way (Fig. 5). It is important to understand that the Agglomeration of Orléans is composed of thousands of nodes and it is strictly impossi- ble to detect these structural differences without the indicators developed in this research.

The situation of the city of Chanteau is quite worrying in terms of risk management. Indeed, there is often no alternative to the disturbance of a single road component, ultimately leading to the isolation of some parts of the city. Fortunately, in this case, the city is not directly exposed to flooding. Nevertheless, for other hazard types, the situation remain problematic. 
Secondly, a specific study has been conducted on the city of Orleans. In this analysis, the road network has been simplified in order to focus study on the main road of Orléans. Thus, the Orléans road network appears to be well meshed and redundant, like most of the French cities. Nevertheless, the redundancy is quite low and close to Orléans' different bridges (Fig. 6).

That is why it is important in terms of risk management to pay special attention to these different bridges which link the north part of the city with the south part. Indeed, these bridges can be easily disconnected and consequently the north and south part of Orléans can also be easily disconnected. The objective for risk managers is to avoid isolation of these two parts. That is why Orléans flood managers have recently begun a more focused analysis about accessibility of these bridges during flooding.

\section{Conclusion}

This paper proposes a methodology to improve urban resilience using Web-GIS. This methodology is based on a system approach of cities. This approach emphasizes the importance of networks concerning urban resilience. Thus, principles and assumptions finally lead to the analysis of how urban networks are able to face natural hazards. This kind of approach is quite new. So, in this article we have demonstrated how networks were the dorsal spine of cities' development, and how they play an important part in resilience. Indeed, economic activities, populations, services and public infrastructures depend on the efficiency and the reliability of these networks. Thus we can admit that powerful networks are a prerequisite to a powerful city.

Many results have already been obtained and contribute to the implementation of the resilience concept in an operational way: an overall methodology about urban resilience has been developed; a framework concerning urban networks' resilience has been implemented; specific structural indicators have been designed in order to assess networks redundancy; these indicators have been tested in real case study; and an operational Web-GIS prototype has also been designed.

To conclude, applications on the Orleans road network attest that methodology and tools are operational. In this context, a strong emphasis is placed on urban planning in order to improve risk management. This research provides the opportunity to deal with these issues. Nevertheless, this research is focused on technical aspect. In fact, social and organizational resilience must be assessed as well to ensure a more holistic approach necessary to improve resilience. Moreover, structural analysis of the road network presented here is just a first step. Others technical networks need to be analyzed and designed indicators need to be adapted to their main characteristics. In-depth analysis, including resistance capacity analysis and recovery capacity analysis, is also underway in another territory.

Acknowledgements. The authors wish to acknowledge with sincere appreciation the reviewers for their comments.

Edited by: B. Barroca

Reviewed by: two anonymous referees

\section{References}

Albert, R., Albert, I., and Nakarado, G.: Structural vulnerability of the North American power grid, Phys. Rev. E., 69, 4 pp., 2004.

Ashley, R., Blanksby, J., Chapman, J., and Zhou, J. J.: Towards Integrated Approaches to Reduced Flood Risk in Urban Areas, edited by: Ashley R., Garvin S., Pasche E., Vassilopoulos A., and Zevenbergen C., Advances in Urban Flood Management, 415432, 2007.

Batty, M.: Cities as Complex Systems: Scaling, Interaction, Networks, Dynamics and Urban Morphologies, in: Encyclopedia of complexity and systems science, edited by: Meyers R. A., Springer, 1041-1071, 2009.

Blancher, P.: Risques et réseaux techniques urbains, Centre d'études sur les réseaux, les transports, l'urbanisme et les constructions publiques (CERTU), 1998.

Brand, F. S. and Jax, K.: Focusing the meaning(s) of resilience: resilience as a descriptive concept and a boundary object, Ecol. Soc., 12, 23, 2007.

Bruneau, M., Chang, S. E., Eguchi, R. T., Lee, G. C., O’Rourke, T. D., Reinhorn, A. M., Shinozuka, M., Tierney, K., Wallace, W. A., and VonWinterfeldti, D.: A Framework to Quantitatively Assess and Enhance the Seismic Resilience of Communities, Earthq. Spectra, 19, 737-738, 2003.

Buhl, J., Gautrais, J., Reeves, N., and Sole, R. V.: Topological patterns in street networks of self18 organized urban settlements, Physica A, 49, 513-522, 2006.

Campanella, T. J.: Urban Resilience and the Recovery of New Orleans, J. Am. Plann. Assoc., 141-146, 2006.

Carpenter, S., Walker, B., Anderies, M., and Abel, N.: From metaphor to measurement: Resilience of what to what?, Ecosystems, 8, 765-781, 2001.

Comfort, L. K., Boin, A., and Demchak, C.: Designing Resilience. Preparing for Extrem Events, Pittsburgh, University of Pittsburgh Press, 2010.

Cutter, S., Barnes, L., Berry, M., Burton, C., Evans, E., Tate, E., and Webb, J.: A place-based model for understanding community resilience to natural disasters, Global Environ. Chang., 18, 598-606, 2008.

De Bruijn, K. M.: Resilience and flood risk management, a system approach applied to lowland rivers, thesis, Delft university, 220 pp., 2005.

Dueñas-Osorio, L.: Interdependent response of networked systems to natural hazards and Intentional disruptions, Dissertation, Georgia Institute of Technology, Atlanta, Georgia TechLibrary, 2005.

EA-UK (Environment Agency United Kingdom): 2007 summer flood reviews, 2007. 
Folke, C.: Resilience: The emergence of a perspective for socialecological systems analyses, Global Environ. Chang., 253-267, 2006.

Gallopin, C. G.: Linkages between vulnerability, resilience, and adaptive capacity, Global Environ. Chang., 16, 293-303, 2006.

Garber, L.: Denial-of-service attacks rip the internet, Computer, April, 33, 12-17, 2000.

Gastner, M. and Newman, M. E. J.: The spatial structure of networks, Eur. Phys. J. B, 49, 247-252, 2006.

Gleyze, J. F.: La vulnérabilité structurelle des réseaux de transports dans un contexte de risque, Thèse de doctorat, Université Paris VII, Laboratoire COGIT-IGN, 826 pp., 2005.

Gunes, A. E. and Kovel, J. P.: Using GIS in emergency management operations, J. Urban Plann. Dev., 126, 126-149, 2000.

Hines, P. and Cotilla-Sanchez, E.: Do topological models provide good information about electricity infrastructure vulnerability?, Chaos, 20, 033122, 2010.

Holling, C. S.: Resilience and stability of ecological systems, Annual Review of Ecological System, 4, 1-23, 1973.

Kinney, R., Crucitti, P., Albert, R., and Latora, V.: Modeling cascading failures in the North American power grid, Eur. Phys. J. B, 46, 101-107, 2005.

Klein, R. J. T., Nicholls, R. J., and Thomalla, F.: Resilience to natural hazards: How useful is this concept?, Environmental Hazards, 5, 35-45, 2003.

Lembo Jr., A., Bonneau, A., and O'Rourke, T.: Integrative technologies in support of GIS-based postdisaster response, Nat. Hazards Rev., 9, 61-69, 2008.

Lhomme, S., Serre, D., Diab, Y., and Laganier, R.: GIS development for urban resilience, Sustainable City 2010, 14-16 April 2010, La Coruña, Spain, 2010.

Lhomme, S., Serre, D., Diab, Y., and Laganier, R.: A Methodology to Produce Interdependent Networks Disturbance Scenarios, Vulnerability, Uncertainty, and Risk: Analysis, Modeling, and Management Proceedings of the ICVRAM 2011 and ISUMA 2011 Conferences, 724-731, 2011.

Manyena, S. B.: The concept of resilience revisited, Disasters, 30, 434-450, 2006.
Matisziw, T. C., Murray, A. T., and Grubesic, T. H.: Exploring the vulnerability of network infrastructure to disruption, Ann. Regional Sci., 43, 307-321, 2008.

Mayunga, J. S.: Understanding and Applying the Concept of Community Disaster Resilience: A capital-based approach, Landscape Archit., 22-28, 2007.

Ouyang, M., Dueñas-Osorio, L., and Min, X.: A three-stage resilience analysis framework for urban infrastructure systems, Structural Safety, 2012.

Pasche, E. and Geisler, T. R.: New strategies of damage reduction in urban areas proned to flood, Urban flood management, in Urban Flood Management, edited by: Szollosi-Nagy, A. and Zevenbergen, C., 101-117, 2005.

Reghezza, M., Rufat, S., Lhomme, S., Djament-Tran, G., and Leblanc A.: Resilience use and abuse, Cybergeo, 2012.

Serulle, N. U.: Transportation Network Resiliency?: A Fuzzy Systems Approach, Master Thesis, Utah State University, 95 pp., 2010.

Sole, R. V., Rosas-Casals, M., Corominas-Murtra, B., and Valverde, S.: Robustness of the European power grids under intentional attack, Phys. Rev. E, 77, 026102, 2008.

Wang, J. W. and Rong, L. L.: Cascade-based attack vulnerability on the US power grid, Safety Science, 47, 1332-1336, 2009.

Wasserman, S. and Faust, K.: Social network analysis: Methods and applications (structural analysis in the social sciences), Cambridge University Press, 2004.

Winkler, J., Dueñas-Osorio, L., Stein, R., and Subramanian, D.: Performance assessment of topologically diverse power systems subjected to hurricane events, Reliab. Eng. Syst. Safe., 95, 323336, 2010.

Zevenbergen, C., Cashman, A., Evelpidou, N., Pasche, E., Garvin, S., and Ashley, R.: Urban Flood Management, CRC Press, 340 pp., 2010.

Zhang, J., Xu, X., Hong, L., Wang, S., and Fei, Q.: Attack vulnerability of self-organizing networks, Safety Science, 50, 443-447, 2012. 